\title{
Innovation and Healing in Contemporary Yup'ik Mask Making
}

\author{
Anna Mossolova Tallinn University
}

\begin{abstract}
This ethnographic study, conducted with seven contemporary Yup'ik carvers examines one of the oldest, but long suppressed, art forms in southwest Alaska - mask making. In-depth individual interviews captured the voices of artists of different ages, backgrounds and experiences, who, as they branch out and push the boundaries of traditional media, keep re-exploring and forging their cultural identity by bringing the forgotten symbols, values and worldviews associated with masks back to life. This article demonstrates how innovation unfolds the healing potential of masks and can help individuals and communities recuperate from a colonial past, and assert positive self-identification as Alaska Indigenous peoples today.
\end{abstract}

Keywords: Yup'ik, Indigenous arts, cultural revival, tradition, innovation, identity, healing

Resumé : Cette enquête ethnographique menée auprès de sept sculpteurs yup'iks contemporains examine l'une des formes d'art les plus anciennes, mais longtemps réprimée, du sud-ouest de l'Alaska: la fabrication de masques. Des entretiens individuels approfondis ont permis de restituer les voix d'artistes d'âges, de milieux et d'expériences différents qui, en se diversifiant et en repoussant les limites des supports traditionnels, ré-explorent et forgent sans cesse leur identité culturelle en faisant revivre les symboles, les valeurs et les visions du monde associés aux masques qui sont tombés dans l'oubli. L'article montre comment l'innovation déploie le potentiel de guérison des masques et peut aider les individus et les communautés à surmonter leur passé colonial et à se définir positivement comme peuples autochtones de l'Alaska d'aujourd'hui.

Mots clés : Yup'ik, arts autochtones, renouveau culturel, tradition, innovation, identité, guérison
For individuals who have experienced the effects of colonialism, where their cultural identity was targeted and they were dehumanized because of it, a reconnection to their culture or a form of cultural restoration becomes the primarily objective of their healing process.

Ferrara $(2018,28)$

\section{Introduction}

7 he history of colonization of Indigenous lands and 1 resources across the globe is also the history of social injustice, cultural oppression and marginalization of Indigenous people. Through inter-cultural contact, the Indigenous populations of North America were exposed to dreadful infectious diseases and subjected to religious conversion, forced relocation, separation from family and community in residential schools, irreversible integration into local and global cash economies, cultural and political marginalization, and other trauma (Kirmayer et al. 2009, 27). In Alaska, the long-term forced extirpation of original socio-cultural practices, such as feasting and gift exchange ceremonies, singing, dancing, and mask making, resulted in a tremendous disruption of traditional knowledge and life-ways of Native communities (see Barker et al. 2010; Crowell et al. 2010; Fienup-Riordan 1996, 2007). ${ }^{1}$

During the past few decades, the production of traditional art forms - mask carving among them - has been undergoing a revival in many Alaska Native communities, including the Yup'ik. ${ }^{2}$ Masks as symbols of cultural continuity and Indigeneity are being brought back to ritual life, used in social exchange and gift-giving, proudly displayed in places where people gather, like cultural and medical centres (Clifford 2013, 279).

The very first attempts to revitalize mask carving and return masks back to dance practice in several Alaska Inuit communities were documented by Fienup-Riordan $(1986$; 1996) in the Yup'ik culture area; Kingston (1999) and Riccio (2003) further north among the Inupiaq; Haakanson and Steffian (2009) and 
Jackinsky-Horrell (2007, 2009) on Kodiak in Sugpiaq communities. The artistic revitalization movement that began ca. thirty years ago continues today, nourishing new conversations about the spiritual and communal significance of Alaska Native arts.

Post-colonial art history and anthropological literature have recognized the shifting of art objects between the categories of "curiosities," ethnographic specimen, souvenirs, and others (Appadurai 1986; Clifford 1988; Phillips 1998) and have investigated the appropriation of Indigenous arts in Western aesthetics (Lee 1991; Marcus and Myers 1995, Phillips and Steiner 1999). Discourses on Alaskan Native art in particular have revolved around the issues of Indigenous identity, cultural resilience and revitalization (Crowell et al. 2001; Fair 2006; Pullar 2008; Jackinsky-Horrell 2012). At the very tip of the spear in these discussions are the artists, who have to navigate complex and often deeply personal issues of selfidentification, artistic expression and spirituality within their communities. Focusing on the fluidity between the past and present mask-making practices in Yup'ik communities and, more importantly, on the values that masks stand for as material expressions of Yup'ik culture today, this article explores how contemporary Yup'ik artists view their own work against its background and what they have to say about the production, use and meaning of masks today.

This article presents the results of ethnographic fieldwork conducted from 2016 to 2018 among Yup'ik mask carvers and includes in-depth interviews and job shadowing of artists' work in their woodworking studios. Thus, this article presents the contemporary practice of Yup'ik mask making, as it was demonstrated, described and interpreted by carvers themselves. It addresses a gap in the present literature on the material culture of Yupiit where only a few ethnographies have touched upon the manufacturing processes of Yup'ik carvers (Fair 2006; Fienup-Riordan 1986, 1996; Himmelheber 1993; Ray 1980, 1981).

As Susan Fair, who was working with Native artists throughout Alaska from the 1970 s to the 2000 s, accurately observed, when you ask a Native artist to tell you about making art, you tend to get a story about survival, metaphorical or practical, instead of a description of hands-on techniques (Fair 2006, xxv). I have often experienced the very same tendency in my conversations with artists. Hence, this article is not only about making things, but is also about the cultural survival of a people whose traditional worldviews and the creation of objects that express and reinforce those worldviews, have been harshly suppressed during several centuries of colonial enterprise in southwestern Alaska.
The artists' voices included in this article echo a common theme: for modern Yup'ik carvers, making masks is a way of remembering the ancestral past and processing the legacy of recent colonial history. In their hands, masks become a means to mend the ruptures in the transmission of traditional values and almostforgotten skills and knowledge. Healing is a relatively under-studied topic in connection to manufacturing and performing Alaska Native arts, but it became a leitmotif in practically all of my conversations with Yup'ik mask carvers and thus cannot be left out of this discussion. As this article shows, the new material and technical innovations that modernize the tradition and introduce present-day connections and meanings to the ancient forms only amplify the healing effects of contemporary mask making.

\section{Oppression and Resilience}

Recent archaeological finds from the Nunalleq site near the village of Quinhagak in southwest Alaska confirm that mask making has significant time-depth in Yup'ik culture (Knecht 2014; Mossolova and Knecht 2019). The Yup'ik people made and used masks of different sizes and meanings centuries before the first Euro-American contact in the 1820s (VanStone 1984, 151). The earliest masks and mask fragments from the Nunalleq site have been dated from ca. the sixteenth century or earlier. They prove a strong continuity in the design and style of the Yup'ik mask-making tradition over time.

According to ethnographic accounts, masks were worn during such ceremonies as Nakaciuq (the Bladder Festival), Kevgiq (Messenger Feast), Elriq (Memorial Feast), but most consistently and specifically with Agayuyaraq (Morrow 1984, 137). During this late-winter ceremony, the Yupiit, through songs and dances and with the help of angalkuq (shaman), tried to influence animals' yuit (their persons) and tuunrat (shamanhelping spirits) to elicit the successful harvest of fish and game and other resources in the new subsistence season (Morrow 1984, 137; Barker et al. 2010, 40). Agayuyaraq, literally "the way of praying or requesting" (FienupRiordan 1996, 307), was "a ceremonial invitation for these spirits into the human world where they were made visible" (Fienup-Riordan 1994, 315). The angalkuq would instruct carvers on how to carve masks according to his visions to manifest the otherwise invisible into material form. Masks were carved in advance, but decorated and painted just before the ceremony to become fully empowered (Morrow 1984, 136-139). Masks were worn to re-enact the past events of spiritual encounters, in which, for example, a tuunraq provided much-needed help, or to narrate hoped-for future events, such as a prosperous 
hunt, and so forth. Masks brought visions into the tangible world of imagery and that image was used to both empower and tell important stories.

For the Yup'ik, dancing with masks used to be a form of prayer, ${ }^{4}$ a way of asking for abundance in fish, animals, and other resources, and a request to Ellam Yua (the spirit of the Universe) for the well-being of entire community (Fienup-Riordan 1996; Barker et al. 2010, 185; Ayunerak et al. 2014, 94). Dancing strengthened community ties, uniting people in times of celebration, but also in times of grief and hardship. As Elders explain, it helped to heal and cleanse the mind and body: "not only did dancing honor the living and the dead, it was also the people's way of ensuring good health, of pushing disease away from the bodies" (Barker et al. 2010, 188-189). The unifying and healing power of dance was highly important and valued.

The Yup'ik ways of making prayers had changed with the arrival of first outsiders - missionaries. Russian Orthodox priests who arrived in southwest Alaska during the 1840s discouraged shamanism, although Yup'ik ceremonialism was generally tolerated until the 1880s, when larger numbers of Protestant and Catholic missionaries settled in the region ${ }^{5}$ (Barker et al. 2010, 21). Less tolerant of masked ceremonies, these missionaries viewed masks as manifestations of evil idolatry, and sought to abolish masked dancing as a dangerous and sinful activity $(139,140)$.

In addition to the intense cultural oppression, epidemics caused rapid social change in the region: diseases introduced by outsiders wiped out at least $60 \%$ of the Yup'ik population by 1838 (Barker et al. 2010, 146). A disastrous flu epidemic at the turn of the twentieth century cut the Yukon-Kuskokwim Delta population in half in just three months, hitting Elders and youngsters particularly hard, leaving survivors leaderless and demoralized. $A n$ galkut were getting old and were not replaced. By the 1930 s, inter-village masked performances had ceased in most Yup'ik communities. Some Catholic communities in the lower Yukon and on the coast did preserve recreational dancing, but without the use of masks (FienupRiordan 1987, 40).

Nonetheless, mask carving in southwestern Alaska did not die out completely, but underwent significant changes after it was separated from its original context - ceremonial dancing. In some coastal and Yukon communities, but also in Bethel, carvers were making masks for sale to make a living (Barker et al. 2010, 177). The growing tourist industry brought explorers, teachers, military officers, governmental employees and other non-Native buyers to the region who viewed masks primarily as objects of art and eagerly purchased or traded for these native "souvenirs." In the aftermath of colonial enterprise, masks, which had never been trade goods in Yup'ik communities, started to be carved as wall décor and shifted from the ceremonial domain to the domain of commodified arts (Clifford 1988; Lee 1999).

Both new religion and commerce significantly influenced the development of mask making in the Yukon-Kuskokwim Delta in many ways. For instance, masks that were made for sale no longer had several functional elements, which most traditional dance masks used to have, as they were no longer essential: there was no need for a mouthpiece on the back of the mask for the dancer to grip with his teeth so as to keep the mask on his face; masks did not need eye holes either, as there was no one behind the mask to look through them (Fienup-Riordan 1987). The eyes were drawn, sometimes carved, but typically not hollowed out. Accounting for the dramatic change in the functionality and iconography of masks carved on Nunivak Island starting from the 1960s, Molly Lee (2000) notices that not only did they become flat and sightless, but also lost any anthropomorphic reference in their style or theme. The adopted religion, primarily the Evangelical Covenant Church, prohibited human imagery: the spirit face (yua) would be of a wolf, fox, or other mammal, but "not a humanoid, as would have been the rule in times past" (Lee 2000, 11).

The size of Yup'ik masks as well as their constituent material also changed. Traditional face-sized masks were made of driftwood and commonly decorated with many carved and painted attachments, which could be easily damaged during transportation from Alaska to the homes of collectors. Buyers were often looking for smaller, simpler pieces. Miniature masks made of walrus tusk ivory, a key commodity in the Euro-American economy, began to dominate the regional arts market and became extremely popular amongst tourist-collectors in the second half of the twentieth century. Additionally, the western notion of artistic authorship was introduced to Native crafts: mask carvers started signing the backs of their works. ${ }^{6}$

In the 1980s, after almost a century of suppression of the Yup'ik dance tradition, the active revitalization of mask making started out as part of wider efforts to reclaim cultural identity. The growing awareness of tremendous social change had awoken in many people a sense of urgency to retain their identity as Yupiit, maintain control of their land and resources, improve their health and sense of well-being, as well as to return to linguistic and cultural traditions, most importantly their masked dances (Barker et al. 2010, 24). Beginning in Catholic communities, the revival of traditional ceremonial activities was subsequently adopted by 
some Moravian and Orthodox communities along the Kuskokwim.

In 1982, the Bethel Native Dance group received a grant from the Alaska State Council on the Arts to revive the use of masks in dancing. Three Yup'ik carvers, including Nick Charles Sr. from Nelson Island, and Kay Hendrickson and John Kusauyuq from Nunivak, produced masks for the Bethel Native Dancers. The mask that Nick Charles carved represented a prophetic vision of a shaman who foretold the arrival of the first kass'aq (white person) in the Yukon-Kuskokwim region. The mask was named after that shaman - Issiisaayuk. "It is perhaps significant that this mask, which represents how the first contact between Yup'ik and Western culture was foretold, should be worn at the first masked dance performed for both Yup'ik and non-Yup'ik people since the missionaries successfully suppressed Yup'ik ceremonial dancing," wrote Ann Fienup-Riordan $(1987,43)$ acknowledging the historic importance of that event.

The touring exhibit Agayuliyaraput: Our Way of Making Prayer in 1996-98 set another crucial milestone on the Yup'ik journey to the revitalization of dancing and mask making. A result of a collaborative project between Yup'ik village communities, museum professionals and an anthropologist Ann Fienup-Riordan this unprecedented exhibit brought fifty masks from museums in Washington, DC, New York, Seattle, and Berlin back to the Yukon-Kuskokwim Delta, where they had been originally obtained by the explorers in the late nineteenth century (Fienup-Riordan 1996, 1999; Clifford 2013). Many Elders and tradition bearers born in the early 1900 s still remembered the names and stories that elicited the meanings of masks. Their remembrances were captured in two catalogues accompanying the exhibit: a "multivocal" scholarly book, The Living Tradition of Yup'ik Masks: Agayuliyararput (Our Way of Making Prayer) (Fienup-Riordan 1996), and a bilingual collection of full-length unannotated stories as they were told by thirty-three Elders and translated by Marie Mead (Mead and Fienup-Riordan 1996). The Agayuliyararput exhibit returned to the communities not just the physical objects, but the knowledge, history and pride for cultural integrity, and artistic vitality that the masks embedded (Fienup-Riordan 1999, 341).

These initial, powerful instances of resilience against colonial oppression contributed significantly to a longterm process of cultural restoration in Yup'ik communities. Today, a few decades after the first efforts to bring mask-making traditions back in the 1990 s, there are around two dozen living Yup'ik Native mask makers working in both rural and urban settings who continue to reconcile the past and to further cultural restoration, which is a process of constant progress.
In her recent book, In Pursuit of Impact: Trauma-and Resilience-Informed Policy Development (2018), Nadia Ferrara takes a holistic approach to understanding the experience of (colonial) trauma, resilience, transformation and healing. Trauma and resilience, Ferrara posits, are two interdependent processes that define our lives. She vividly describes how, targeted against cultural continuity of Indigenous Peoples, colonial trauma impacted entire communities. If left unresolved, this gets transferred into each successive generation, affecting further individuals' identity, cultural pride and their sense of place in the world, all of which are absolutely critical to human well-being $(2018,16)$. Throughout the book she illustrates how trauma can be transformative and can foster individual and collective resilience, a dynamic pathway on which "one responds to adversity, adapts to it, learns and transforms from it" $(2018,39)$. Ferrara invites us to rethink, or in her words, "humanize" trauma and resilience by focusing on the voices and narratives of intergenerational trauma survivors, because they are the "tools that support decolonization" $(2018,23)$. They aid the transmission of cultural values and beliefs and contribute to the meaning-making process, so much-needed in times of adversity $(2018,49)$. In the following sections, I present the voices and image narratives of contemporary Yup'ik carvers with whom I had the privilege to work and learn from.

\section{Yup'ik Mask Carvers: Then and Now}

The seven mask carvers I worked with in the past few years in Anchorage and Bethel, the regional centre of the Yukon-Kuskokwim Delta, represent diverse ages, backgrounds and had diverse life experiences. These artists, some of whom were experienced and others were emerging, were invited to the study because of the community-recognized proficiency of their artistic work, which went far beyond the simple replication of basic ethnographic designs common in parts of the Alaska Native arts market. Though having different artistic styles and unique signatures, these artists shared similar visions and rationales for carving masks. The conversations we had were about the manufacturing process and innovations that are often perceived as being in conflict with the notion of authenticity, about artists' attempts to re-root traditional symbols and values in the present-day, and most importantly, about individual and communal healing though art and tradition.

Only a few of them grew up making masks or had the opportunity to watch somebody practice this art form. The old Yup'ik ways of learning by observing others and trial and error were not an option for the artists who were raised in urban environment, nor even 
for those who grew up in a village. Most of the Elders in villages who witnessed and remembered the masked dances of the old days in a qasgiq ${ }^{7}$ were no longer around to pass on the knowledge and share their stories. Most of these contemporary carvers ${ }^{8}$ had to learn carving not from culture bearers in their communities, but through formal education, that is, by attending carving classes and courses, researching museum collections, studying ethnographic books and art catalogues (like the one of the Agayuliyararput exhibit), and so forth. They might not have grown up knowing the original protocols of the Yupiit forms of prayer, but through studying and engaging in mask making, they have discovered the way back to their cultural values and identity. Participation in the restoration of artistic practices of the past gives them back the control over their cultural narratives, helping to build new, healthy connections with the complex cultural legacy they inherited, and strengthen their self-identification as Alaska Native artists.

Wood carving is a difficult skill to master. As a rule, modern carvers take their first steps in mask making by trying to replicate some old ethnographic pieces from museum collections. For most of the artists, making replicas is not an attempt to blindly copy traditional forms, but a learning journey into materials, techniques and meanings behind the original piece.

Knowledge that derives from museums and ethnographic literature is complemented by natural and intuitive ways of creating. Many of the modern carvers refer to genetic memory as a source of knowledge and inspiration for their artwork: "I don't even know where that comes from, but it's really from my genes and my ancestors", says Drew Michael (Drew Michael, interview, 7 April 2016). As a child, Drew was adopted out of his culture and raised in Western urban environment. At the age of 14, he attended his first carving class led by renowned Inupiaq carver, Joe Senungatuk. This lifechanging experience set Drew on a continuous journey into reclaiming his cultural identity.

Another esteemed mask carver, Phillip John Aarnaquq Charette, almost echoes the same thought, claiming that, "when I do the work, I know how to do it, it's imprinted in me. It comes naturally. It just happens" (Phillip Charette interview, 26 April 2016). Yup'ik was Phillip's first language, but the school system he went through had an effective assimilation and acculturation agenda. The defining moment that started his artistic career was when he received copies of the Agayuliyararput catalogue and, in his own words, "it showed him the direction he needed to go." Like Drew, Phillip had a formal education in art as well as extensively researching Yup'ik mask-making traditions on his own, studying books, and visiting large ethnographic collections, like those at the Smithsonian.

It is no wonder that the carving process as such, and especially mask carving, generates a sense of belonging and communal connection that these modern Native artists absorb and, in turn, reflect back to others through their work. Back in the days, Yupiit were constantly working with wood. Hunting and carving skills were equally important, as people had to make and mend their own tools to provide and survive. In a fieldwork report (1936-37), ethnographer Hans Himmelheber (1993, 55) even questioned the concept of the artist as a person with outstanding abilities: in the Yukon-Kuskokwim Delta, carving was not an exclusive skill, everyone who could carve did so. The crafting rules were not enshrined as a doctrine, and everyone could participate in artistic activity.

The entire ceremonial cycle for which masks were carved would help secure the prosperous hunting season and assure the well-being of the community. The notion of personhood in the traditional Yup'ik worldview extends beyond the human domain to include animals and other nonhuman/supernatural beings, sentient beings such as driftwood, and even natural phenomena, such as the weather. Along with animal masks, a mask of the north wind, for example, would be carved to pray for the consistent wind during the spring that brings fish from the ocean to the areas where it could be harvested (Earl Atchak, interview, 25 June 2017). Even driftwood, which is an extremely important resource in the treeless Yukon-Kuskokwim tundra and is used for everything kayak making, house building, steam bathing - would be honoured with a mask representing its spirit.

Earl Atchak, an artist from Chevak who has been carving masks for over thirty years, said his ancestors believed that, long ago, when the Yukon ice would break up in the spring, each piece of wood floating down the river had a spirit. Each piece would know what it was going to become. One would end up rotting on the beach; another one would be picked up for a steam bath and would be burned; but some knew that a mask maker would pick them up and make them into a mask. Nowadays, many carvers I talked to still claimed that they did not choose their wood, but that the wood called to them.

Carvers consider driftwood as an acting living being that enters into a personal relationship with a carver (Gell 1998). Earl explained:

that root [of a spruce tree] draws me, and I want to do something with it. It might be there [on the tundra] for a couple of days. I keep passing it. [...] That wood has its own little life. And you know, I want to 
go back. So finally I go out there and I cut off certain pieces $[. .$.$] and bring it in. And I start working away.$

Earl treats his wood as a partner, as an artist itself. "I am not the artist; the wood is the artist!" he confesses (Earl Atchak, interview, 25 June 2017).

Another Chevak-born artist, Moses Tulim, acknowledges the same idea of partnership and uniqueness of every single piece of wood: "every individual piece of artwork is different: the wood patterns, the wood shape, the rings come out in unique ways. They're like fingerprints. [...] They never come out the same. And each piece of wood tells its own story and that's what I like to bring out" (Moses Tulim, interview, 5 June 2016). Moses didn't grow up making masks or watching others make masks, but he was exposed to Yup'ik stories and legends, including the ones of "little people"9 who can change into the shape of animals, plants, and other objects to avoid being seen. These stories became the main theme in the imagery of his masks. Moses believes that mask making is a way to tell and preserve these stories that teach us traditional Yup'ik values.

As explained earlier, all men in the village used to carve, but some carved better than others, and a shaman could commission a recognized carver to make a mask according to his vision. Masks were made shortly before they were used, very practically, not driven by creative or artistic desires (Himmelheber 1993, 52-53). Observing the work of contemporary mask carvers, one can ascertain no personal separation between the conception and the execution of the artwork reported by early ethnographers exists in the mask-making process today. Contemporary artists craft the masks that speak to both the ancient and newer aspects of their heritage. This dialogue between the past and the present is expressed in the ways masks are made and in the stories they tell.

\section{"It Is Not Traditional, But It Is Traditional" 10}

Both the toolkit and the range of materials available to contemporary mask carvers became significantly diversified and modernized over time. Along with handmade tools - an adze, bent knives or gouges - today's carvers use power tools like bandsaws, grinders, and rotary tools that are especially useful when shaping and outlining initial forms (Figure 1). Power tools make the carver's work much faster. Tradition and innovation are blended in the modern practices of making art, which has raised public discussion on authenticity, ownership, and cultural appropriation in all parts of the Indigenous world (Abbott 1994; Marcus and Myers 1995; Phillips and Steiner 1999).

That said, wood remains the most typical material used in contemporary mask-making: carvers living and

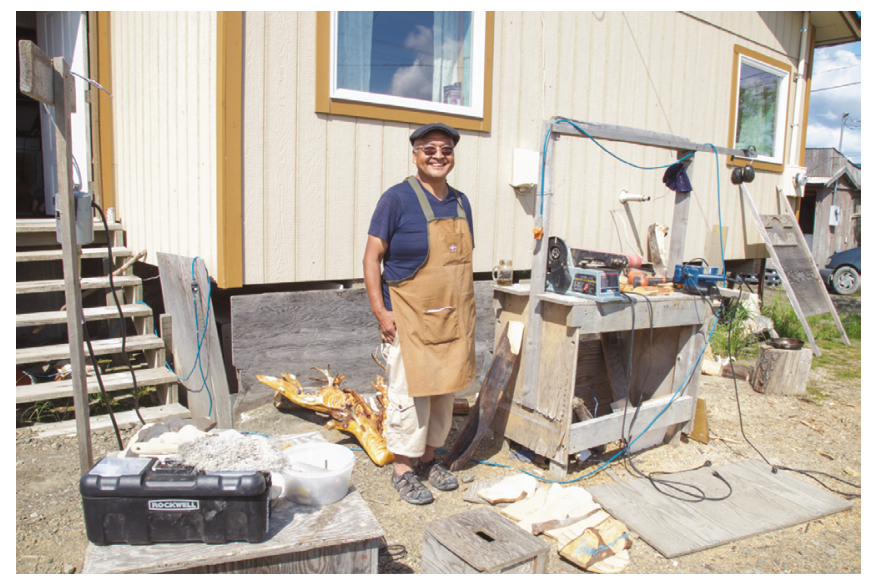

Figure 1: Bethel mask maker Moses Tulim surrounded by his power tools in the shop outside his home (photo courtesy of the author).

working in the Yukon-Kuskokwim Delta continue to work with driftwood, as did their predecessors. They often prefer the bottom parts of the trunk or the roots of cottonwood or spruce, but drifted spruce and cottonwood are not the only types of wood that carvers use nowadays. Modern Yup'ik artists, especially the ones working in cities, have access to a wider variety of timber, and tend to use wood that is not common in Alaska, for example, basswood or redwood. Soft and straightgrained, these woods are easy to carve. Masks made of ivory, clay, ${ }^{11}$ metal, or other media are also found among contemporary masks.

As Elders recall, obtaining materials for mask making was a time and energy consuming enterprise, sometimes even a dangerous one (Fienup-Riordan 2007, 57-59). Even today, when describing how they get materials for their craftwork, mask makers from the Delta often say, "I harvest [my materials]" or "I hunt [my materials]". The latter may refer to both a metaphoric act of hunting and searching, as well as an actual hunt - one goes hunting animals or birds to get sinew, bone, tusk ivory, or feathers, which are then used in mask carving and decoration.

Mike McIntyre, a young mask maker who grew up in Bethel in a family that had preserved many Yup'ik traditions, including mask carving, doesn't buy his pigments. Instead, he gets his white clay, red ochre and blue vivianite from his grandfather, George Nevak, who lives in Toksook Bay. The way Mike describes how the pigments are collected resembles a story of pursuing and killing game:

my grandpa [...] he goes out on a boat with a gun and he rides around mountains and he shoots the mountains and like, you know, he shoots there, then it drops 


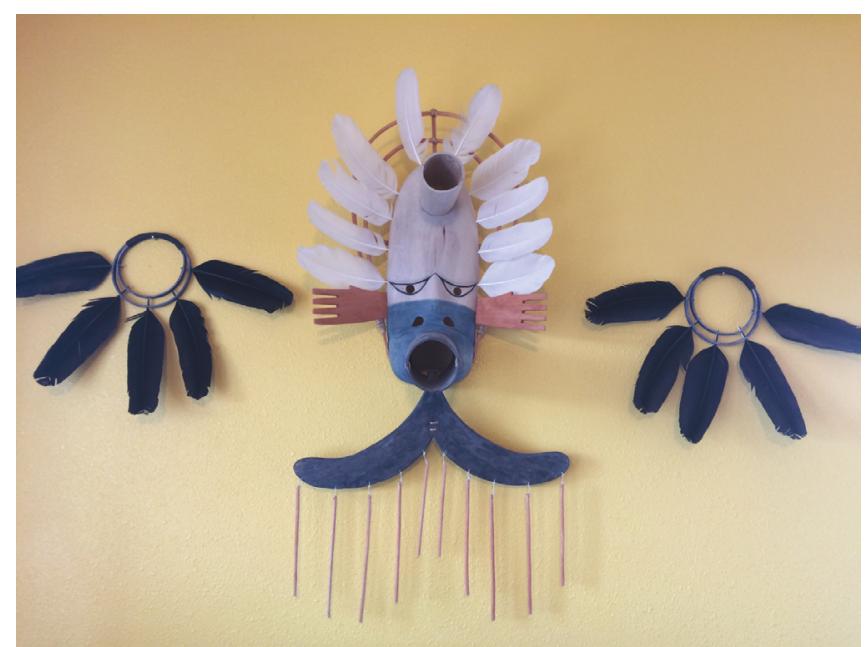

Figure 2: "Tomanik" (Wind-maker) mask and a set of dance fans by Mike McIntyre. This mask is a replica of a mask collected by A. H. Twitchell in Napaskiak in the early 1900s. (photo courtesy of the author).

down and he looks with the binoculars if there is red, blue or white because [there is that paint]". (Mike McIntyre, interview, 2 June 2016)

Living in the Yukon-Kuskokwim Delta, Mike, who considers himself "classically trained" in Yup'ik traditional arts, prefers harvesting, trading and using natural materials. However, even he may use a permanent marker to draw the fine black contours around the eyes of his mask (Figure 2).

Today, an extraordinary variety of organic materials, such as porcupine quills, ivory, fur, skins, bone, grass, feathers, sticks and twigs are combined with newer media such as oil paints, acrylics, plastic, nails, synthetic threads, barbwire, beads, semi-precious stones, and even Swarovski crystals. Craft supplies shops and hardware stores or online shops become the "hunting-grounds" of contemporary artists as when it comes to mask decoration, especially, there is little that contemporary mask makers do not employ to realize their visions.

Innovation is, nonetheless, not always a result of the abundance and availability of materials, but also their lack or a ban on their use. Today's legislation restricts the materials Alaska Native artists can sell as part of their artwork. Regulations and prohibitions are being put forward that would prohibit the selling of art; these include certain bird feathers or walrus tusk ivory. According to the Marine Mammal Protection Act, for example, hunting marine mammals (or using their by-products) for art is illegal for an artist who is less than one-quarter Alaska Native by blood quantum. This is in itself a problematic approach for determining one's cultural affiliation (see discussion in Langdon 2016).

Drew, who has been confronted many times with the question about his work being "too modern," in the use of contemporary materials and tools, is perplexed:

\begin{abstract}
Somehow when you look at masks or any kind of Indigenous art, people expect it to [...] look a certain way and be used in a certain way and to be made of certain materials and then even the processes [...] we're supposed to use like the same tools as were always used, but I don't know why that everyone puts Indigenous art into a box like that. (Drew Michael, interview, 7 April 2016)
\end{abstract}

The strict division of art into "traditional" and "contemporary" seems to be artificial and uncomfortable, not only to Drew, but to most of the Yup'ik artists I talked to. Most artists had difficulties explaining what is or is not actually "traditional" in their art. In using the term "traditional", they often referred to the ways their forefathers would do things or the designs and styles of ethnographic masks they had seen in museums or books. Mike described "traditional" as something intergenerational and in which its meaning can be grasped simply by looking at it, without reading a description on the wall, something in the repeated styles or design elements, and something that tells the stories of his culture. Something that his father would approve of.

In her study on the revival of Native art forms, Susan Fair posits that the categorization of Indigenous art into "traditional" and "contemporary" is generally troublesome to Native artists from all over Alaska. Imposed by non-Native outsiders, collectors or donors, these categories are a political product and part of a Western vocabulary that does not reflect the Native way of thinking or making things (Fair 2006, xxii-xxiv). To avoid the trap of this often counter-productive and oppositional terminology, one needs to understand tradition as a process, as a "creative interpretation of the foundations of belief and thinking" (Hill 1992, 11), and if the thinking evolves, then the art inevitably reflects the dynamics of that thinking. Pre-contact Yup'ik culture was already in constant flux, with innovations in tools, materials and styles that were never static. Indigenous cultures should not be expected to freeze in time, with their material culture staying unchanged since the time of contact. Like western art, Alaska Native art also cannot remain in stagnation or limit itself to replications of old forms disregarding historical or social changes.

Tradition for the artists is clearly something rooted in the past, but growing in the present and affecting the 
future. Many gaps in knowledge of making traditional things due to the disruptions in intergenerational knowledge transfer caused by colonialism are being replaced by innovation and creative new interpretations. While job-shadowing modern artists, one can see how tradition is being continually recreated and reinvented by people living it. Drew explains:

I'm always trying to expand and use new things. It is fun because whatever culture you are in, and wherever you are at, it is going to reflect whatever is happening at the time. [...] If you look at mask from like a hundred years ago people were using the materials that they had around them. [...] People have always used whatever is available to them at the time.

The revitalization of Native arts opens up a whole new potential for the exploration and reinvention of modes of production, allowing new, individual styles to emerge.

Tradition goes well beyond materiality. Modern tools or nonconventional materials do not necessarily bring conceptual discontinuity into mask making, as long as shared stories and values are still being transmitted. As Phillip put it:

the best way to hold and retain stories is to manifest those stories and bring them back; because when you look at our traditional values [...] those values can still come out and manifest themselves. You may have to make a translation from what that value originally intended to what your current life is, and how you apply it. (Phillip Charette, interview, 26 April 2016)

Through the revitalization of traditional arts, modern artists extract these stories, and with the help of new materials and tools, translate these "lived realities" (Ferrara 2015) in the here-and-now, thus nurturing the sense of communal belonging and intergenerational connectedness. The following section looks at some examples of how certain cultural symbols and stories embodied in modern masks bind them more strongly to the traditional belief and value system of Yupiit, and more so than any fidelity to conventional materials.

\section{A Multilayered Universe, Transformation and Pukuk}

In the Yukon-Kuskokwim Delta, mask designs varied from one village to another. Nonetheless, a certain number of stylistic and structural characteristics could still be identified as part of a symbolic language recognizable across the region, allowing us to identify and talk about a discretely Yup'ik style for masks (Wallen 1990). Most of the time, these iconographic motifs reflect the primary concepts of Yupiit worldview.
For instance, many contemporary masks, like their historical predecessors, have bentwood hoops around the main body of a mask (see, for example, Figures 2 and 3). Beyond their pragmatic function, which is to hold the entire construction of the mask and its tiny detailed appendages together, the hoop is a key element in understanding the symbolic concept of Yup'ik masks. The word for the wooden hoop is ellanguaq. It derives from ella-, translated as weather, world, universe, awareness, plus (ng)uaq, which is to pretend (Fienup-Riordan 1987, $43,47)$. A ringed mask can thus be viewed as a model of the multilayered universe manifesting the interconnectedness of multiple, physical and spiritual, layers of Yup'ik cosmology. Furthermore, a hooped mask is another visual symbolization of Ellam iinga, or the eye of awareness, widely present already in the pre-contact Yup'ik iconography and sometimes referred to as "the circle and the dot" motif. Facilitating transformation, masks in Yupiit traditional dance ceremonies had both the implications of supernatural vision (they are the eyes into other worlds) and transition: "the circle and dot is a concrete metaphor for and means to achieve a dynamic movement between worlds, be it spiritual cycling, supernatural vision, or social transformation" (Fienup-Riordan 1987, 43-44).

Typically, the hoop would be made out of wood that was steamed and then bent into shape. As an alternative to bentwood, Drew works with the thin slices of wood called veneer (used in furniture manufacturing) that he fashions into partial or complete, round or geometrically designed hoops. Veneer comes in rolls, is easy to bend, and is backed with glue, which makes it very easy to laminate pieces together and/or fix them in a new shape. This modern technological know-how does not interfere with the traditional view of the hoop: for Drew, it is still a physical manifestation of the interconnectedness and movement between the worlds (Drew, interview, 6 April 2016).

For centuries, Indigenous peoples across the north built their worldview around the balance of relationships between human, animal and supernatural beings (Ingold 2000; Kirmayer et al. 2009, 444). Spiritual cycling and the extension of respect to animals and other elements of the natural world are fundamental to an understanding of Yupiit relationships with their environment. Many masks I have seen being made by contemporary artists still have symbols that demonstrate these paramount principles. The pierced and thumbless hands (often a prominent iconographic feature of tuunrat, or tunghat, the shamans' helping spirits) attached to the hoops or directly to the main body of the masks were, according to ethnographic accounts, used “to indicate the spirits' willingness to allow, by impairing their grasp, many animals to slip through their fingers, thus ensuring the continued 


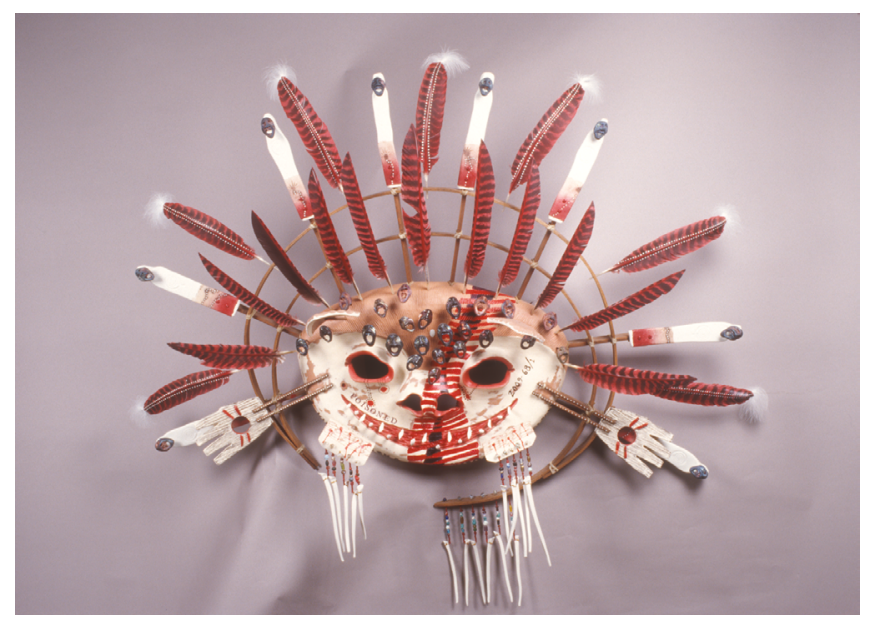

Figure 3: Phillip John Aarnaquq Charette's mask "Poisoned Large," 2009. This piece, made of clay and porcelain, was inspired by Yup'ik masks that Phillip studied at the Smithsonian; early curators and collectors used to treat masks in arsenic, stamping "poisoned" on them. (photo courtesy of the Burke Museum of Natural History and Culture, catalogue number 2009-61/1).

abundance of animals on earth" (Fitzhugh and Kaplan 1982, 202). Phillip also interprets those thumbless hands that appear on many of his masks as a visual warning to remind people not to over-harvest the surrounding resources. Without a thumb, people cannot grab whatever they want (Figure 3).

To convey fundamental cultural values through art, modern artists do not necessarily rely on ancient conventions of design and symbolism. Rather they tend to experiment and express traditional values via non-traditional materials. One of the few female mask carvers I know in Alaska, Andrea Akerelrea, grew up in Anchorage spending summers in the village of Scammon Bay, where her family comes from. Disconnected from the Native way of living, Andrea confesses that she is not "a traditional Yup'ik" and she seeks for answers to the questions that many urban Native artists have: "What makes one Native?" Is it his/her genes, blood content, or the way of living or knowledge about his/her culture? (Andrea Akerelrea, interview, 29 August 2017).

As a young artist, Andrea experimented with many different types of materials: She has made masks of wood, metal and clay. While exploring the ways in which traditional materials can be used in a non-traditional manner and vice versa in her art class, Andrea created an installation of drums. She collected some grocery shopping bags, ironed them together and stretched them over the metal rods. Plastic bags perfectly mimicked the skin covering of traditional drums. The metal frames of Andrea's drums were welded together in a way that allowed installation to move and to produce the sound. Andrea's art piece compares recycling with rebirth and reminds us to be not wasteful and live purposefully, "to live pukuking life," explains Andrea. Pukuk literally means suck the meat off bones, or eat every edible part of an animal or fish. By doing this, you honour the animal killed and pray for its return in the next harvesting season, because if one is not respectful, animals will not allow themselves to be taken. Andrea encourages her children to stay connected to their culture and live by its fundamental values, like pukuking.

Masks have always constituted a crucial part of community bonding ceremonies - times of celebration, grieving, remembrance were manifested in dances with masks. By bringing this craftsmanship forward to serve contemporary needs, today's Native carvers are trying to bring back not so much the materials or carving techniques that were lost, but values and connections embodied in different elements of their art. This example of Andrea's work beautifully illustrates that material can be the message itself, and that a contemporary invention can represent a paramount value not worse than conventional media.

Their own life experiences convinced carvers that mask making has a genuine and valuable healing effect in helping people, Native and non-Native alike, culturally re-connect with their roots, reconcile, and search within themselves to connect with others, past and present. As the following section will show, modern materials or innovations in manufacturing processes may in fact make the story behind the mask more powerful in a present-day context, ease the translation between what is of the past and what is of the present, and unlock not only individual, but also communal healing actions.

\section{Healing}

The consequences of colonialism and continuing tensions between the values of local communities and mainstream society has driven Indigenous artists to forge their cultural identity. Making things traditional to one's culture is deeply therapeutic on many levels: It connects a person to the land through the gathering of materials, connects a person with a community, and connects an individual to their culture, ancestors and spirit (Cultural Resources for Alaska Families: Traditional Health \& Wellness Guide 2018,32 ). When people are able to carve masks, make regalia or other traditional objects, they develop a stronger sense of who they are and where they belong (Pullar 2008,112 ). They articulate their identity and cultural values through physical manifestations, through art that has a critical quality to release intangible experiences in 
tangible forms. Working with her Cree patients, Ferrara found (2004) that art therapy had proven itself to be a more successful form of healing than talk therapy. Art making in many Indigenous communities is not being viewed as a leisure or activity reserved for talented ones only, but as part of the way of living (Ferrara 2004, 8). I believe the artists I worked with would agree that art making became a self-guided therapy for them too, their way of healing.

In anthropology, healing is a very broad term. Ferrara $(2004,105)$ herself defines healing as a process of "creating a new self by deconstructing the old, redefining the components, and building a new, multidimensional and more harmonious self". Healing is also understood as renewal in the work of Kirmayer and Valaskakis (2009), who describe healing through tradition as an individual or collective spiritual process rooted in the recovery and reconfiguration of almost-forgotten traditions to meet the challenges of the contemporary world. In this capacity - healing is not only to return to an initial state of health or mind, but also a reconfiguring of past, traumatic experiences - healing through tradition is synonymous with another emerging anthropological concept, that of recuperation. The latter is explained by Jane I. Guyer $(2017,89)$ as a post-traumatic process of "imaginative extraction of something of value from the past, and its revival and reconfiguration for the present and future." The restoration of artistic and ceremonial practices of one's culture and their modern transformations therefore creates the vital conditions for healing efforts.

Healing through tradition means healing through engagement with cultural symbols and narratives. Mask making and performing evokes the re-articulation of traditional beliefs and rituals enabling the mechanisms of symbolic healing (Dow 1986; Kirmayer 1993, 2004; Kirmayer at al 2009; Lévi-Strauss 1967). As Dow (1986, 56) explains, symbolic healing is a process in which the healer re-creates and "particularizes" a mythic world and manipulates culturally-specific symbols in order to assist bodily, emotional and/or social transactions in a person/ community. In a manner of speaking, contemporary artists take on the same role - they assist personal and/ or collective transformations by creating objects that are intrinsic to their culture's model of reality (Ferrara 2004, 120).

Innovation accompanying the restoration of culture is not necessarily a refutation of tradition; it is what fills the gaps and mends the disruptions in the continuance of tradition. Like the artists I learned from, I view innovation as a natural phenomenon, but also as a response to cultural discontinuity caused by colonial trauma. Referring again to Ferrara (2018, 40), after a traumatic experience, one cannot return to an initial, pre-traumatic state, but rather one attains a new normal, that of an evolved and transformed self. Adaptability toward change and openness to transformation are thus two key characteristics of resilience (Ferrara 2018). As a type of transformation, innovation is a critical component in one's healing process.

The concept of transformation is a key not only to healing, but also to the understanding of the nature of indigenous arts in general. The best Native-made artistic works have been always valued not for their aesthetic qualities, but for their capacity to transduce and establish harmony between different realms (Dufrene 1991, 123). Good art has a transcendental capacity. All mask makers I worked with returned to the theme that working on masks opens a kind of portal to their own culture, helping them reconnect with themselves, their communities and their ancestors.

Mask making initiates healing not only as manual therapy - working with the hands and manipulating materials is certainly therapeutic, calming and meditative, providing the opportunity for the maker to process their inner thoughts and emotions - but also more immediate healing, which comes primarily from visual storytelling and mythopoetic thinking, including its metonymic and metaphoric associations. The artwork and the myth share many qualities: Both can be seen as texts, as forms of expression that help address inconsistencies in one's self - and in regard to both myth and mask - the product cannot be separated from the process that produced it (Ferrara 2004, 12; 123). Through (visual) narration, the artist transforms the dimly seen spirit world into the light of the tangible form, acknowledges it, and then releases it to the larger world. This is how Phillip describes the process of working on his masks:

it takes something which is intangible and you make
it tangible. You give it voice. You make it concrete.
You bring it out of the spiritual thought, or something,
and you manifest it. Then people can look at it and
process it. I think that's the real gift - creating work
that connects something in the past, bring something
of who we are to the present that we can process and
articulate and make that connection [...] That's part
of the process of healing (Phillip Charette interview,
26 April 2016).

A traumatic experience often affects one's ability to cope and can be characterized as the loss of control or as a state of powerlessness (Ferrara 2018, 13). By sharing narratives and expressing traumatic personal and cultural experiences in the public sphere, artists release 
tension, accumulate the power of resilience, and thus, regain control over their identities.

For his first solo show, Phillip did a piece called "Apa" (in Yup'ik informally "grandfather"), dedicated to Phillip's grandfather's generation, which was forced to assimilate and to forget who they were and from where they came. Phillip made the mask's face look ashen and grey; he tied its mouth shut, as people were not allowed to speak their language or participate in their traditions. For the hoops around the mask, Phillip used barbed wire. He also made some feathers out of barbed wire and inserted them into the hoops, he bent them forward and had porcelain crosses hanging from the feathers in front of the face replacing the cosmology from which Native communities were banned. Phillip also placed a mirror behind the eyeholes, so that the beholders could see their own reflection in the eyes of the mask and see themselves as part of the story of that generation, in either one way (as the oppressed) or another (as the oppressor). Phillip wanted his grandfather's voice to come out of this piece and tell his story.

Missionaries banned mask making for several generations, turning it into a tradition of the oppressed. Today, mask making pays it back by becoming a means of reconnecting with one's roots through acknowledging and processing this historical trauma. As Phillip elaborates, masks "have the capacity to bridge that gap [between past, present or future], to create a pathway, to create a doorway into something that goes beyond just a physical part of who we are".

In another example of this idea, Drew likes to use either a wood-burning tool or a propane torch, to burn his works in a decorative way and to connect to the symbolic act of burning the masks after their use, an act documented in earlier ethnographies (Fienup-Riordan 1996, 43): after being "danced" in a ceremony, the mask would be destroyed, usually by burning to release its story into the spirit world.

In October 2016, Drew actually burned a series of ten large masks, which represented ten prevalent diseases within the state of Alaska, including diabetes, cancer, HIV, behavioural health problems, alcoholism, and fetal alcohol syndrome among others. Carved by Drew and carefully painted by Elizabeth Ellis, these unusually large, three by five-foot masks portray the "faces" of diseases at the macroscopic level. The masks toured around the state to raise awareness and engage Native communities in a sensitive conversation about diseases and their effects. As part of the exhibit, visitors were allowed to sign or share stories of their own experiences with the diseases on the backs of the masks. After three years of travelling, the journey of

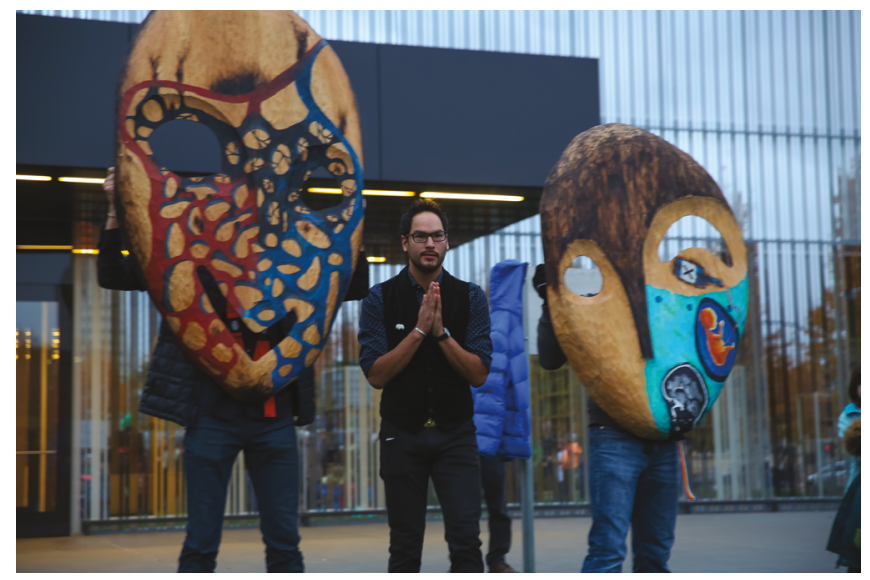

Figure 4: Drew Michael and his masks. Opening Prayer at Mask Burning Ceremony, Anchorage Museum (photo courtesy of Jackie Kramer).

the masks was over and the stories they had collected waited to be released. The burning ceremony on the lawn of the Anchorage Museum gathered hundreds of community members. Before being burned, the masks were danced (Figure 4).

These masks were rather unconventional in their size, imagery, and style. Nonetheless, the evocative burning ceremony spoke to participants, mostly because it addressed crucial societal issues, but also because it called forth communal memories and resonated with almost forgotten rituals of the past. The healing power of Drew's artistic action came from a shared heritage and the feeling of communion, reinforced by the emotionally charged symbols. Carved for community bonding and healing rituals, masks have always functioned as "transactional symbols" (Dow 1986, 64-66) that are taken from the mythic world to assist in the transformation of emotions and actions; or as "metaphors" (Kirmayer 1993; Kirmayer at al. 2009, 441) which make it possible to re-describe individual or collective experiences in new terms. This is why, for healing efforts in Alaska Native communities today, masks play such a crucial role and have an enormous therapeutic potential: As they represent the value of cultural experiences, a necessary precondition for healing, but also because the very nature of masks is liminal and transformative. Masks fundamentally communicate the transitioning and mediation between the visible and the invisible, the concealment of one entity and the revelation of another one, the reconciliation of "me" and "not-me" (Emigh 1996, 22). The transformative power of masks is hard to overstate, especially when the masks find their way back to their original context. 


\section{Danceable Masks}

The results of successful efforts to revive Yup'ik dancing can be witnessed at the annual Cama-i Festival in Bethel that celebrates Alaska Native cultures and traditions with a three-day gathering of dance groups from all over the Delta. Nonetheless, most Yup'ik dance groups still perform without masks. Mike McIntyre's father, culture bearer John McIntyre, explains that in the past, masks were tightly connected to songs that were performed at such gatherings. This core relationship of masks and Yup'ik dance ceremonies had discontinued after masks were removed from the dances, and many songs were forgotten (John McIntyre, personal communication, 14 January 2016). One of the challenges confronted by contemporary mask makers has been to reconnect songs and masks and take masks off the walls and back to their original context.

Over 30 years later, after that influential maskmaking workshop in Bethel, which sought to restore Yup'ik dancing traditions by bringing masks back to the dances, a grandson of one of three carvers, Benjamin Charles, continues what his grandfather Nick Charles started with his fellows back in 1980s. An emerging young mask maker, Ben did not pick up carving until recently. In his own words, it came to him as a personal awakening: "a lot of things I grew up around, I didn't pay attention to; my eyes were closed" (Benjamin Charles, interview, 30 June 2017). His journey of a return to his culture and traditional values was accelerated through an intense carving practice. Ben spent the winter of 201718 carving masks, dancing sticks and other garments for the dance groups to use at the 2018 Cama-i Dance Festival (Figure 5).

Gifting his six masks to the dance groups gave Ben a sense of "peace and determination" (Benjamin Charles, personal communication, 17 March 2018). Seeing so many young dancers performing with masks at the festival was an important landmark not only for the carver but for the entire community to witness the resumption of the tradition and connection between three fundamental Yup'ik art forms: the dance, the song and the mask.

That summer, Ben carved another mask for another very historic event in the Yup'ik community: the grand opening of the Nunalleq Culture and Archaeology Center in the village of Quinhagak (in which I had the honour and pleasure of participating). This community-based and operated museum now holds the largest existing collection of pre-contact Yup'ik artifacts, recovered from an archaeological site exposed to coastal erosion, dating back to $1400-1670 \mathrm{CE}$, near the village.

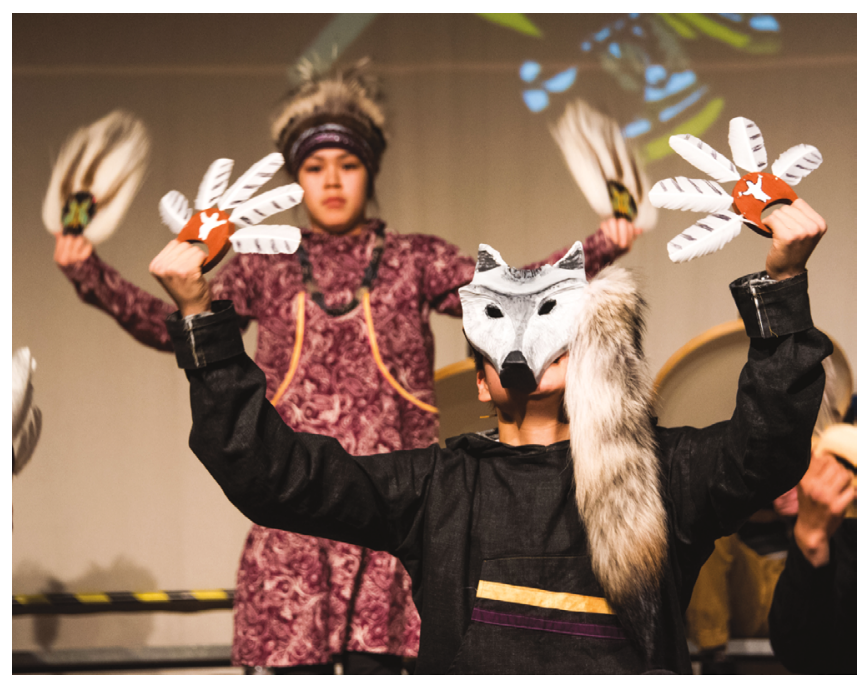

Figure 5: 2018 Cama-i Dance Festival featuring a wolf mask created by Benjamin Maxmillion Charles (photo courtesy of Rocky Grime).

A group of Quinhagak children, who grew up visiting the dig site almost every summer from 2009 to 2018, composed a song and dedicated it to their ancestors who used to live at the old village. They performed the song and the dance at the opening ceremony. One of the male dancers was wearing a mask with walrus tusk that Ben had carved for the dance group a night prior to the opening. A 500-year-old human-walrus transformation mask found at the site years earlier inspired the design of that mask. Nonetheless, Ben's mask looked much happier and less frightening than the original. Watching the first masked dance being performed in the village in more than a century, a number of Elders and community members cried.

Both examples, Drew Michael's mask burning ceremony and Ben Charles' masks being danced at various celebrations, clearly demonstrate that while the design and creation process manifests individual resilience and heals the artists themselves (as the carvers state), the incorporation of masks into dancing, in turn, also becomes instrumental in the efforts of communal recuperation and, more broadly, the empowerment of cultural restoration.

In the right context and with the spirit of Yup'ik values within them, masks today, whether or not they are carved with modern tools or made of non-conventional materials, offer an opportunity for the same expression of spiritual release and transition as centuries before. A sense of cultural continuity creates a sense of security (Ferrara 2004, 119). Like healers who mediated and restored balance between different worlds in liminal states 


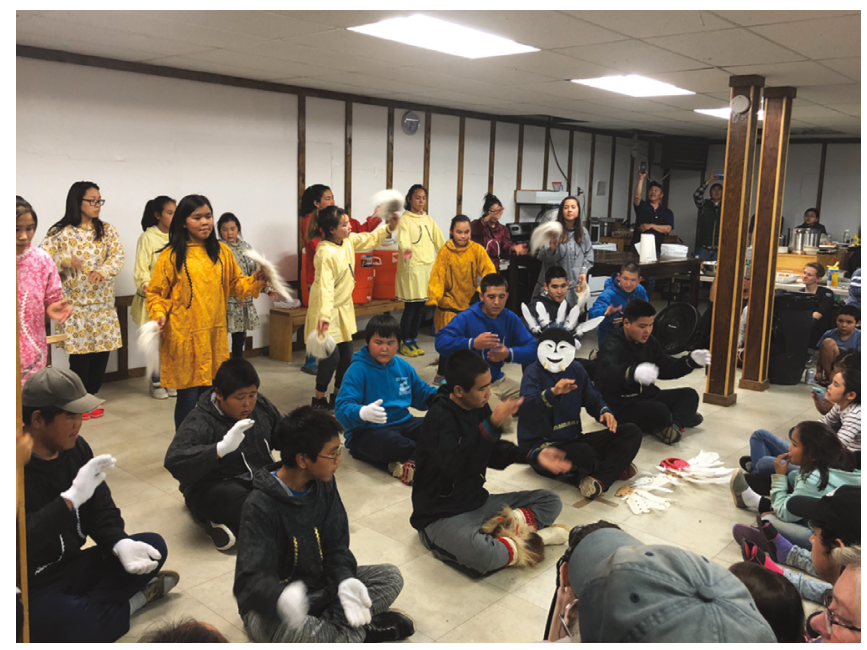

Figure 6: Quinhagak dance group performing their Nunalleq song composed and dedicated to the dig. Young dancer Peter Smith is wearing a walrus mask made by Benjamin Charles. (photo courtesy of author).

with the use of masks, contemporary Yup'ik carvers in their present attempts at cultural resilience are trying to negotiate a more balanced self and secure collective well-being by re-rooting it in cultural narratives, rituals and values.

\section{Conclusion}

The production of artistic works in Indigenous communities was never about aesthetics as much as it was about survival and adaptation. As the interviewed artists underlined, connections between past and present built and manifested in material forms go far beyond materiality. By absorbing and moving beyond fading memories of the ethnographic past with their artwork, contemporary Alaska Native artists secure the continuity of mask-making tradition, and the value system attached to it, into the future. It is not enough just to remember. Stories and symbols of the past need to be translated and re-introduced into present-day contexts, helping communities that have been forced to relinquish their language and customs to re-engage with the worldviews and the ways of living of their ancestors.

As this article has shown, a seeming conflict between "traditional" and "modern" ways of making things is more of a socio-economic construct, viewed by artists as a counterproductive debate imposed on them. It is not just that innovation is natural, good or inevitable, but it is this act of innovation that makes tradition live again. New manufacturing techniques and media give old symbols modern interpretation and, most importantly, ground them in the here-and-now, bringing the past into the present. Innovation by no means devalues the meaning of modern artwork or makes it less "authentic"; on the contrary, it enriches and furthers tradition, and allows for it to unfold its healing potential.

Making masks and watching them be danced again after a long period of silence imposed by colonialism fosters not only an individual healing for the artists themselves, but enables a cultural restoration for the entire community. The revival of cultural practices, which defined Indigenous peoples for centuries prior to Euro-American contact, nurtures healing and well-being in the Alaska Native communities today, restoring a much-needed sense of security, belonging, engagement and positive cultural identity.

\section{Anna Mossolova, School of Humanities, Tallinn University,Estonia.Email: anna.mossolova@gmail. com.}

\section{Acknowledgements}

My deepest gratitude goes to Drew Michael, John and Michael McIntyre, Phillip John Charette, Moses Tulim, Andrea Akerelrea, Earl Atchak, and Benjamin Charles for sharing the stories of their lives and artwork with me. I also want to thank two incredible Sugpiaq artists, Alvin Amason and Perry Eaton, for patiently teaching me carving, and all my classmates at Alaska Native Arts class at UAA for their trust and support. Quyana cakneq! I would like to express my special appreciation to Dr. Rick Knecht and Dr. Hugo Reinert for their valuable suggestions on this paper and their ongoing encouragement of my research. I also would like to acknowledge my UAA advisor, Dr. Medeia Csoba-DeHaas, for her guidance and help through the IRB review process. Finally, my appreciation goes to the late Dr. Sonja Luehrmann and anonymous reviewers for their careful reading of the manuscript and insightful comments. This research was conducted with the generous support of the Fulbright Foreign Student Program, the European Regional Development Fund (Dora Pluss Program) and the TÜHI Research Fund of Tallinn University.

\section{Notes}

1 I use the term Indigenous when talking about communities across the north (or world in general); however, when talking about Alaska communities, I prefer the term Native, as this is presently the most commonly used term by which Indigenous peoples across Alaska refer to themselves. 
2 Yup'ik people (plural Yupiit) belong to the Eskimo-Aleut family of languages. They are the largest Native population in Alaska traditionally inhabiting the Yukon-Kuskokwim Delta, including the coast and the tundra between the mouths of two rivers.

3 In ethnographic literature, this ceremony is also referred to as Kelek (from keleq-, “to invite to one's home”) or Itruka'ar (from iter-, "to enter or come into a habitation") (see Fienup-Riordan 1996, 40, 63).

4 The word agayu today means "to pray," but originally it was a word for a ceremonial mask (Mead and FienupRiordan 1996, 27, 229).

5 Moravian missionaries settled in Bethel in 1885, and three years later, Jesuits established their mission on Nelson Island (Barker et al. 2010, 21).

6 Although it is interesting to note that until recently, most Indigenous artwork was displayed at the museum according to tribal and/or geographic affiliation rather than individual artist, even if the artist was known.

7 A traditional Yup'ik men's house meant for communal and ceremonial gatherings.

8 Most of the time, masks are not the only art form they create.

9 "Little people" or ircenrraat (plural), also spelled as ircenrrat, is one category of Yup'ik legendary and extraordinary persons. See more in Fienup-Riordan (1994, 63-87).

10 A quote from Mike McIntyre, interviewed on 2 June 2016.

11 In fact, both clay and ivory are traditional materials for Yup'ik craftsmanship, but they were not typical media for mask making.

\section{References}

Abbott, Lawrence. 1994. "Contemporary Native Art I: A Bibliography.” American Indian Quarterly 29 (3-4): 383403. www.jstor.org/stable/1184743

— 1998. "Contemporary Native Art II: A Bibliography." American Indian Quarterly 22: 98-103. www.jstor.org/ stable/1185110

Appadurai, Arjun. 1986. The Social Life of Things: Commodities in Cultural Perspective. New York: Cambridge University Press.

Ayunerak, Paula, Deborah Alstrom, Charles Moses, James, Charlie Sr., and Stacy M. Rasmus. 2014. "Yup'ik Culture and Context in Southwest Alaska: Community Member Perspectives of Tradition, Social Change, and Prevention." American Journal of Community Psychology 54: 91-99. https://doi.org/10.1007/s10464-014-9652-4

Alaska Department of Health and Social Services. 2018. Cultural Resources for Alaska Families: Traditional Health \& Wellness Guide. Anchorage: State of Alaska. http://dhss.alaska.gov/ocs/Documents/Publications/pdf/ CulturalResourcesGuide.pdf.

Barker, James, Ann Fienup-Riordan, and Theresa John. 2010. Yupiit Yuraryarait/Yup'ik Ways of Dancing. Fairbanks: University of Alaska Press.

Clifford, James. 1988. The Predicament of Culture:

Twentieth-Century Ethnography, Literature, and Art. Cambridge, MA: Harvard University Press.

- 2013. Returns: Becoming Indigenous in the TwentyFirst Century. Cambridge: Harvard University Press.
Crowell, Aron, Amy F. Steffian, and Gordon L. Pullar, eds. 2001. Looking Both Ways: Heritage and Identity of the Alutiiq People. Fairbanks: University of Alaska Press.

Crowell, Aron L., Rosita Worl, Paul C. Ongtooguk, and Dawn D. Biddison, eds. 2010. Living Our Cultures, Sharing Our Heritage: The First Peoples of Alaska. Washington, DC: Smithsonian Books.

Dow, James. 1986. "Universal Aspects of Symbolic Healing: A Theoretical Synthesis." American Anthropologist 88 (1): 56-69. https://doi.org/10.1525/aa.1986.88.1.02a00040

Dufrene, Phoebe. 1991. "Utilizing the Arts for Healing from a Native American Perspective: Implications For Creative Arts Therapies." Canadian Journal of Native Studies 10 (1): 121-131. http://www3.brandonu.ca/cjns/10.1/dufrene. pdf

Emigh, John. 1996. Masked Performance: The Play of Self and Other in Ritual and Theatre. Philadelphia: University of Pennsylvania Press.

Fair, Susan W. 2006. Alaska Native Art: Tradition, Innovation, Continuity. Fairbanks: University of Alaska Press.

Ferrara, Nadia. 2004. Healing Through Art: Ritualized Space and Cree Identity. Montreal and Kingston: McGill-Queen's University Press.

- 2015. Reconciling and Rehumanizing IndigenousSettler Relations: An Applied Anthropological Perspective. Lanham, MD: Lexington Books.

—. 2018. In Pursuit of Impact: Trauma- and Resilience-Informed Policy Development. Lanham, MD: Lexington Books.

Fienup-Riordan, Ann. 1986. "Nick Charles, Sr.” In Artists behind the Work: Life Histories of Nick Charles, Sr. Frances Demientieff, Lena Sours, Jennie Thlunaut edited by Ann Fienup-Riordan and Suzi Jones. Fairbanks, Alaska: University of Alaska Museum. . 1987. "The Mask: The Eye of the Dance." Arctic Anthropology 24 (2): 40-55. www.jstor.org/stable/40316143

—. 1994. Boundaries and Passages: Rule and Ritual in Yup'ik Eskimo Oral Tradition. Norman, OK: University of Oklahoma Press.

- 1996. The Living Tradition of Yup'ik Masks: Agayuliyararput, Our Way of Making Prayer. Seattle: University of Washington Press.

_. 1999. "Collaboration on Display: A Yup'ik Eskimo Exhibit at Three National Museums". American Anthropologist 101 (2): 339-358. https://doi.org/10.1525/ aa.1999.101.2.339

—. 2007. Yuungnaqpiallerput. The Way We Genuinely Live. Masterworks of Yup'ik Science and Survival. Seattle: University of Washington Press with Anchorage Museum Association and Calista Elders Council.

Fitzhugh, William W., and Susan A. Kaplan.1982. Inua: Spirit World of the Bering Sea Eskimo. Washington: Smithsonian Institution Press.

Gell, Alfred. 1998. Art and Agency: An Anthropological Theory. Oxford: Clarendon Press.

Guyer, Jane I. 2017. "Aftermaths and Recuperation in Anthropology." HAU: Journal of Ethnographic Theory 7 (1): 81-103. https://doi.org/10.14318/hau7.1.011

Hill, Richard W. Sr. 1992. Creativity Is Our Tradition: Three Decades of Contemporary Indian Art at the Institute of 
American Indian Arts. Santa Fe: Institute of American Indian and Alaska Native Culture and Arts Development.

Himmelheber, Hans. 1993. Eskimo Artists: Fieldwork in Alaska, June 1936 until April 193\%. University of Alaska Press.

Ingold, Tim. 2000. The Perception of the Environment: Essays in Livelihood, Dwelling, and Skill. London and New York: Routledge.

Jackinsky-Horrell, Nadia. 2007. Masks as a Means to Cultural Remembrance: Contemporary Alutiiq Mask Making. MA thesis, University of Washington.

_ 2009. "Contemporary Alutiiq Mask Making".

AlterNative: An International Journal of Indigenous Peoples 5 (2): 73-87. https://doi. org/10.1177/117718010900500106

—. 2012. Alaska Native Artistic Revitalization. $\mathrm{PhD}$ dissertation, University of Washington.

Kingston, Deanna. 1999. Returning: Twentieth Century Performances of the King Island Wolf Dance. PhD thesis. University of Alaska Fairbanks.

Kirmayer, Laurence J. 1993. "Healing and the Invention of Metaphor: The Effectiveness of Symbols Revisited". Culture, Medicine and Psychiatry 17: 161-195. https://doi. org/10.1007/BF01379325

Kirmayer, Laurence J. 2004. "The Cultural Diversity of Healing: Meaning, Metaphor and Mechanism.” British Medical Bulletin 69 (1): 33-48. https://doi.org/10.1093/bmb/ldh006

Kirmayer, Laurence J., Gregory M. Brass, and Gail Guthrie Valaskakis. 2009. "Conclusion: Healing / Invention / Tradition.” In Healing Traditions: The Mental Health of Aboriginal Peoples in Canada, edited by Laurence J. Kirmayer and Gail Guthrie Valaskakis, 440-472. Vancouver and Toronto: UBC Press.

Kirmayer, Laurence J., and Gail Guthrie Valaskakis, eds. 2009. Healing Traditions. The Mental Health of Aboriginal Peoples in Canada. Vancouver and Toronto: UBC Press.

Knecht, Rick. 2014. "Nunalleq, Rescuing an Eskimo Village from the Sea.” British Archaeology 136: 42-49. http://www. britisharchaeology.org/ba136

Molly Lee. 1991. "Appropriating the Primitive: Turn-of-the-Century Collections and Display". Arctic Anthropology 28 (1): 6-15. https:/www.jstor.org/ stable/40316287?seq=1\#metadata info tab contents

_. 1999. "Tourism and Taste Cultures: Collecting Native Art in Alaska at the Turn of the Twentieth Century". In Unpacking Culture: Art and Commodity in Colonial and Postcolonial Worlds, edited by Ruth B. Phillips and Christopher B. Steiner, 267-281. Berkeley: University of California Press.
- 2000. "Spirits Into Seabirds: The Role of the Evangelical Covenant Church of Alaska in the Stylistic Transformation of Nunivak Island Yup'ik [Eskimo] Masks". Museum Anthropology 24 (1): 5-13. https://doi. org/10.1525/mua.2000.24.1.5

Lévi-Strauss, Claude. 1967. Structural Anthropology. New York: Basic Books.

Langdon, Steve J. 2016. Determination of Alaska Native Status under the Marine Mammal Protection Act, A Research Report. Juneau: Sealaska Heritage Institute. http:/www.sealaskaheritage.org/sites/default/files/ MMPAFinalReport.pdf

Marcus, George E., and Fred R. Myers, eds. 1995. The Traffic in Culture: Refiguring Art and Anthropology. Berkeley: University of California Press.

Mossolova, Anna, and Rick Knecht. 2019. "Bridging Past and Present: A Study of Precontact Yup'ik Masks from the Nunalleq Site, Alaska”. Arctic Anthropology 56 (1): 18-38. https://doi.org/10.3368/aa.56.1.18

Phillips, Ruth. 1998. Trading Identities: Native Art and the Souvenir in Northeastern North America, 1700-1900. Seattle: University of Washington Press.

Phillips, Ruth B., and Christopher B. Steiner, eds. 1999. Unpacking Culture: Art and Commodity in Colonial and Postcolonial Worlds. Berkeley: University of California.

Pullar, Gordon. L. 2008. "Repatriation, Cultural Revitalization and Indigenous Healing in Alaska." In Utimut: Past Heritage - Future Partnerships, Discussions on Repatriation in the 21st Century, edited by Mille Gabriel and Jens Dahl. Nunatta Katersugaasivia Allagaateqarfialu/ International Work Group for Indigenous Affairs.

Ray, Dorothy J. 1980 [1961]. Artists of the Tundra and the Sea. Seattle: University of Washington Press. 1981 [1967]. Eskimo Masks: Art and Ceremony. Seattle: University of Washington Press.

Riccio, Thomas. 2003. Reinventing Traditional Alaska Native Performance. New York: Mellen Press.

VanStone, James M. 1984. "Exploration and Contac History of Western Alaska". In Handbook of North American Indians: Arctic, volume 5, edited by David Damas, 149160. Washington DC: Smithsonian Institution Press.

Wallen, Lynn A. 1990. The Face of Dance: Yup'ik Eskimo Masks from Alaska. Calgary: Glenbow Museum.

—. 1999. "The Milotte Mask Collection.” Concepts. Technical Paper Number 2. Juneau: Alaska State Museums. 